\title{
Mobile Blogging as A Mean to Improve Journalism Education
}

\author{
https://doi.org/10.3991/ijim.v14i21.18465
}

\author{
Alexandr Rozhkov ( $\left.{ }^{\square}\right)$ \\ Al-Farabi Kazakh National University, Almaty, Kazakhstan \\ alex.rozhkovl1erambler.ru, \\ Alexander.Rozhkov@kaznu.kz \\ Madina Bulatova \\ L.N. Gumilyov Eurasian National University, \\ Nur-Sultan, Kazakhstan \\ Larissa Noda \\ Al-Farabi Kazakh National University, Almaty, Kazakhstan
}

\begin{abstract}
On the basis of new experimental data, the present paper was aimed at analyzing the effectiveness of training journalism students through the use of blogs. This study included a field survey, during which the impressions of journalism students from the introduction of blogging in the educational process were analyzed. The examination involved 71 undergraduate journalism students of two Russian and two Kazakhstan universities. Innovative teaching strategies were introduced in the training process of mentioned institutions, and the corresponding methods of conducting specialized classes were developed. The experimental data confirmed several hypotheses related to the effectiveness of blogging in journalism education. The practical significance of the obtained results lies in the fact that the proposed approach allows the effective implementation of blogs in journalism training.
\end{abstract}

Keywords - Blog, mobile learning, journalism, learning effectiveness, online media

\section{Introduction}

The development of mobile technologies has affected online media, leading to a revolutionary change in their format. The concept of Web 2.0 implies attracting Internet users to create content that fills the media space $[1,2]$. Being a multidimensional and multifunctional mechanism, modern journalism is impossible without an online segment [3]. Network communication with mobile devices underlies a fundamentally new form of media, which is reflected in the appearance of modern approaches to the structuring and presentation of online publications [4]. The main challenge of modern journalism is the consolidation of traditional offline practices with newly created and continuously developing online including mobile methods [5]. 
Under the current conditions, the issue of training journalism students remains a non-trivial innovative mobile task that requires constant reviewing, monitoring, and analysis of innovative practices and mobile journalism genres, as well as revising curricula and introducing new teaching methods and tools [6]. Blogs are recognized as an efficient social media tool in training journalists [7]. Students can learn to use the latest web technologies, form and update the blog content with mobile applications, conduct online discussions with readers. Thus, a blog, even an educational one, is an essential part of the online journalism environment $[8,9]$.

It should be noted that, despite the more than 20-year history of online journalism, the process of creating new approaches cannot be considered finished [10]. Most of these approaches realize by mobile technologies, which provide the opportunity to constantly be in the center of events, easily exchange content on the fly and with the help of specialized applications constantly develop new formats and capabilities [11]. Accordingly, there is an urgent need to analyze these processes, presented in appropriate scientific research $[8,12]$. The principal tasks of such studies include collecting relevant empirical data, examining the influence of mobile blogs on the formation of professional and universal competencies, as well as qualitative and quantitative assessment of the effectiveness of journalism training while applying innovative methods and technologies.

The current work proposes an approach that allows the effective use of blogging for the preparation of journalism students. The scientific novelty of the study is that it examines the effectiveness of mobile blogging for organizing journalism mobile and blended education. The presented experimental data confirm the positive effect of the proposed training method.

\section{$2 \quad$ Literature Review}

Recent scientific works in the field of journalism education objectively identify similarities between the development trends of web journalism and the requirements for the journalists' professional training [13]. The ability to think in media and web categories can only arise if there is an appropriate experience in their use [14]. Blogs serve as the most flexible and versatile platform, using mobile technologies for building such an experience. At the same time, in journalism, a blog is seen as a form of the author's project, through which a person brings his/her way of understanding reality to the audience [15].

The advantages of blogs and their preference over other types of media, that accompany the development of professional journalistic skills, include [16,17]:

- User-friendly publishing mechanisms and intuitive interfaces.

- Simplicity and free-of-charge basis.

- Functional similarity of various blogging platforms, both long-existing and recent.

- Hypermedia features that allow students to practice inserting hypertext links and experiment with a range of media formats (video, audio, text, image, etc.).

- Clearly defined chronological sequence of posts.

- Possibility of manifestation of the author's personality and self-presentation; 
- Similarity with genres of thematic columns or essays.

- Inclusion of mechanisms for stimulating interactivity in the form of user comments and feedback from instructors and peers.

- Interactivity, discussion, and inviting readers (including teachers and colleagues) to collaborate and argue on some situations through comments.

- Active influence through persuasion, both on the readers and by the readers themselves.

- Stimulation of interactivity in the form of user comments.

- Constant access and control of updates anywhere and anytime thanks to mobile devices.

- Ability to research various readerships.

- Support for collaborative news production conducted from any location.

- Capacity to enhance the visibility of student projects and showcase online portfolios useful to graduates entering the job market.

- Development of personal media brands through the promotion in social networks.

- Increase of students' initiative of and responsibility for the provided information.

- Support of the cutting-edge trends of modern pedagogy in the realistic development of professions, such as student-oriented [18], case-oriented, and projectoriented approaches [19].

The possibilities of using mobile blogs for journalism students' training began to be actively examined since the 2000s [20,21]. However, the central attention was paid rather to the discussions on the general usefulness of blogging, than its efficient application in mobile education $[10,22,23]$. Thus, the concept of mobile blogging as a significant component of journalism training was formed only in the last decade, which once again underlines the dynamic development of this field [24].

In the Russian Federation, studies and discussions on related topics took place in the early 2010s, when, along with online publications, the Russian blogosphere was especially productive. The concept of a virtual social learning environment enables an innovative distribution of roles in the educational process. In such a manner, the teacher can become the author, while the student acts as the reader and vice versa [25]. The student's active position in the learning process is expressed in independence both when creating an own blog and when commenting on others. Additional learning scenarios are realized when journalism students rate their classmates' blogs based on the proposed checklists [26].

The concept of media convergence is widely used to analyze modern journalism and the transformation of journalism education [27]. Convergence refers to the technological aspects of the publications' transition to digital and then - to mobile format, with a common mobile multimedia platform for all text, sound, and video materials. These days, online journalism is still developing, and the curriculum for journalism students is modernizing under the influence of technological progress [28]. Russian researchers note that the phenomenon of the rapid development of online journalism is due to the Internet contribution not only to the mobile adaptation of already existing genres but also to the synthesis of new ones (video reporting, podcasts, live inter- 
views, etc.). This point is also crucial for improving mobile journalism training programs in higher educational institutions [29,30].

Currently, the most necessary mobile journalistic skills include real-time information broadcasting, cooperation with readers, application of several multimodal communication channels, understanding of cyberculture and online media ecosystem, application of conceptual knowledge, and the use of technological tools. All these competencies can be fully acquired in the process of developing and maintaining a blog with appropriate mobile instruments since it is very close to real professional practice.

\section{Problem Statement}

Recent investigations conducted in Russian and Kazakhstan universities did not contain any empirical data confirming the effectiveness of mobile blogging in journalism education. Furthermore, the development of universal and professional competencies, required by Federal State Educational Standards, received insufficient attention. The effectiveness factors in teaching journalism students blogging skills were not adequately described. Examinations performed in Western Europe and the USA allowed assessing the development of some professional skills. However, the data collected were fragmentary and insufficiently representative. Nevertheless, journalism mobile training is a specific task for mobile and blended education, and the collection of experimental data remains crucial to a well-reasoned organization of teaching.

This paper was based on new experimental data and aimed at analyzing the effectiveness of the organization of mobile journalism students' preparation with the use of blogs. In order to achieve this goal, mobile blogging was implemented into the education process of journalism students in Russian and Kazakhstan universities. For the implementation to be successful, the methodology for conducting practical classes in a number of specialized disciplines was improved. During the study, a questionnaire was developed to perform a statistical experiment, analyze the consequences after the blogging introduction, and test the following four hypotheses:

- H1: Mobile blogging develops students' journalistic skills.

- H2: Mobile blogging motivates journalism students to make more efforts in acquiring new knowledge.

- H3: Mobile blogging ensures the satisfaction of student with the educational process.

- H4: Mobile blogging enhances the motivation of journalism students to perform professional activities.

\section{$4 \quad$ Materials and Methods}

For the present research, literature analysis, comparative analysis, mathematical statistics, and a statistical experiment were used. The examination was carried out through the field survey, during which the impressions of journalism students from 
the introduction of mobile blogging practices in the educational process were collected and analyzed. The study was carried out in 2019 among undergraduate students in Journalism at Astrakhan State University (ASU), Pacific National University (PNU, Khabarovsk), Kostanay State University named after A. Baitursynov (KSU, Kostanay), and International Information Technology University (IITU, Almaty). The characteristics of the created sample are presented in Table 1.

Table 1. Characteristics of the sample

\begin{tabular}{|l|c|c|c|c|c|c|}
\hline & ASU & PNU & KSU & IITU & Average & Total \\
\hline Total number of respondents & 19 & 17 & 21 & 14 & 18 & 71 \\
\hline Men, number & 7 & 9 & 11 & 5 & 8 & 32 \\
\hline Men, \% & $36.8 \%$ & $52.9 \%$ & $52.4 \%$ & $35.7 \%$ & - & $45.1 \%$ \\
\hline Women, number & 12 & 8 & 10 & 9 & 10 & 39 \\
\hline Women, \% & $63.2 \%$ & $47.1 \%$ & $47.6 \%$ & $64.3 \%$ & - & $54.9 \%$ \\
\hline Average age & 21.2 & 20.7 & 20.4 & 20.9 & 20.8 & - \\
\hline Number of questionnaires & 19 & 15 & 18 & 12 & 16 & 64 \\
\hline Questionnaires accepted for processing, \% & $100 \%$ & $88.2 \%$ & $85.7 \%$ & $85.7 \%$ & - & $90.1 \%$ \\
\hline Blogging students, number & 8 & 6 & 4 & 2 & 5 & 20 \\
\hline Blogging students, \% & $42.1 \%$ & $40.0 \%$ & $22.2 \%$ & $16.7 \%$ & - & $31.3 \%$ \\
\hline
\end{tabular}

The number of journalism students in the experimental groups ranged from 14 to 21 . The total number of respondents equaled 71 (45.1\% of men and $54.9 \%$ of women). Depending on the university, the number of male respondents ranged from $35.7 \%$ to $52.9 \%$, and female - from $47.1 \%$ to $64.3 \%$. The average age of the participants constituted 20.8 years. In total, 64 questionnaires were received for processing, which amounted to $90.1 \%$ of students in the experimental groups. Before the investigation, the involved respondents were interviewed on having journalistic blogs in any format. Thus, it was found that 20 people $(30.1 \%$ of respondents) already maintain a blog. The main objectives of this experiment were as follows:

- Introduce advanced technologies in the educational process and train journalism students mobile blogging skills.

- Improve students' independent working skills in order to obtain professional competencies.

- Increase the motivation and interest of journalism students in the study of academic disciplines, as well as in professional activity.

- Ensure students' satisfaction with the mobile learning process.

The developed questionnaire included six statements according to which students had to take the position "agree", "disagree", or "not sure". The survey was conducted at the end of the semester, in which the professional blogging practice was introduced. The truth or falsity of the formulated hypotheses was verified through the answers on the following questionnaire statements: 
- "Mobile blogging develops professional skills in journalism" was used to test hypothesis $\mathrm{H} 1$;

- "Mobile blogging motivates to gain new knowledge" was used to test hypothesis $\mathrm{H} 2$;

- "In general, I am satisfied with how training involving mobile blogs is organized" and "It is advisable to increase the number of mobile training hours devoted to blogging" were used to test hypothesis $\mathrm{H} 3$;

- "Mobile blogging is important for a career in journalism" and "In the future, I am going to continue publishing materials on my blog" were used to test the hypothesis $\mathrm{H} 4$.

\section{$5 \quad$ Results}

In experimental groups, mobile blogging was introduced into practical classes in the disciplines History and Theory of Media and Theory of Communication (depending on the university). Students who already had a personal blog could continue developing the existing resource, while others should create it. For this aim, Google Blogger was recommended as a convenient blogging platform with appropriate mobile application.

Practical lessons were held once a week. For each class, participants were given an individual task to prepare a text of 3000 characters on topics related to the discipline. In addition, students worked in groups of two and three, performing mutual evaluation and commenting on each other's materials together with their instructors. At each practical class, the assignments' results were discussed in detail by all the participants. Furthermore, during the study course, training sessions on blog commenting and realtime responding to positive and negative comments were performed. The questioning of students was carried out at the end of the semester. As a result, 64 survey forms with valid data were accepted for processing (ASU - 19, PNU - 15, KSU - 18, and IITU - 12). The average value of forms for all considered universities was 16.

The survey outcomes are presented in Table 2 . The average results were based on the entire sample of students and were not the arithmetic average for four universities. The questionnaire is supplemented by data on changes in the number of students who regularly post materials on personal journalistic blogs (value in brackets). The visualization of the average values of the survey results is presented in Fig. 1. It includes six pie charts, indicated by numbers from 1 to 6 , corresponding to six sections of the questionnaire. The white color of the diagram refers to the "agree" answer, gray refers to "not sure", while black refers to the "disagree" option. 
Table 2. The results of a survey among journalism students

\begin{tabular}{|c|c|c|c|c|c|}
\hline & ASU & PNU & KSU & IITU & Average \\
\hline \multicolumn{6}{|c|}{$\begin{array}{l}\text { 1. Mobile blogging develops professional skills in journal- } \\
\text { ism }\end{array}$} \\
\hline Agree & $94.7 \%$ & \begin{tabular}{|l|}
$80.0 \%$ \\
\end{tabular} & $83.3 \%$ & $83.3 \%$ & $85.9 \%$ \\
\hline Not sure & $5.3 \%$ & \begin{tabular}{|l|}
$13.3 \%$ \\
\end{tabular} & $11.1 \%$ & $16.7 \%$ & $10.9 \%$ \\
\hline Disagree & $0 \%$ & $6.7 \%$ & $5.6 \%$ & $0 \%$ & $3.1 \%$ \\
\hline \multicolumn{6}{|l|}{ 2. Mobile blogging motivates to gain new knowledge } \\
\hline Agree & $63.2 \%$ & \begin{tabular}{|l|}
$73.3 \%$ \\
\end{tabular} & $55.6 \%$ & $75 \%$ & $65.6 \%$ \\
\hline Not sure & $26.3 \%$ & $20 \%$ & $27.8 \%$ & $16.7 \%$ & $23.4 \%$ \\
\hline Disagree & $10.5 \%$ & $6.7 \%$ & $16.7 \%$ & $8.3 \%$ & $10.9 \%$ \\
\hline \multicolumn{6}{|c|}{$\begin{array}{l}\text { 3. In general, I am satisfied with how training involving } \\
\text { mobile blogs is organized }\end{array}$} \\
\hline Agree & $84.2 \%$ & $80 \%$ & $83.3 \%$ & $66.7 \%$ & $79.7 \%$ \\
\hline Not sure & $5.3 \%$ & $13.3 \%$ & $5.6 \%$ & $16.7 \%$ & $9.4 \%$ \\
\hline Disagree & $10.5 \%$ & $6.7 \%$ & $11.1 \%$ & $16.7 \%$ & $10.9 \%$ \\
\hline \multicolumn{6}{|c|}{$\begin{array}{l}\text { 4. It is advisable to increase the number of mobile training } \\
\text { hours devoted to blogging }\end{array}$} \\
\hline Agree & $73.7 \%$ & $60 \%$ & $55.6 \%$ & $58.3 \%$ & $62.5 \%$ \\
\hline Not sure & $15.8 \%$ & \begin{tabular}{|l|}
$26.7 \%$ \\
\end{tabular} & $27.8 \%$ & $25.0 \%$ & $23.4 \%$ \\
\hline \begin{tabular}{|l} 
Disagree \\
\end{tabular} & $10.5 \%$ & \begin{tabular}{|l|}
$13.3 \%$ \\
\end{tabular} & $16.7 \%$ & $16.7 \%$ & $14.1 \%$ \\
\hline \multicolumn{6}{|c|}{ 5. Mobile blogging is important for a career in journalism } \\
\hline Agree & $78.9 \%$ & $73.3 \%$ & $88.9 \%$ & $83.3 \%$ & $81.3 \%$ \\
\hline Not sure & $15.8 \%$ & $13.3 \%$ & $5.6 \%$ & $16.7 \%$ & $12.5 \%$ \\
\hline Disagree & $5.3 \%$ & $13.3 \%$ & $5.6 \%$ & $0 \%$ & $6.3 \%$ \\
\hline \multicolumn{6}{|c|}{$\begin{array}{l}\text { 6. In the future, I am going to continue publishing materi- } \\
\text { als on my blog }\end{array}$} \\
\hline Agree & $73.7 \%$ & $73.3 \%$ & $72.2 \%$ & $75.0 \%$ & $73.4 \%$ \\
\hline Not sure & $21.1 \%$ & $13.3 \%$ & $22.2 \%$ & $16.7 \%$ & $18.8 \%$ \\
\hline Disagree & $5.3 \%$ & $13.3 \%$ & $5.6 \%$ & $8.3 \%$ & $7.8 \%$ \\
\hline Number of active bloggers before the study & 8 & 6 & 4 & 2 & $5(20)$ \\
\hline Number of active bloggers at the end of the study & 14 & 11 & 13 & 9 & $12(47)$ \\
\hline Increase in the number of active bloggers & $175 \%$ & $183.3 \%$ & $325 \%$ & $450 \%$ & $235 \%$ \\
\hline
\end{tabular}



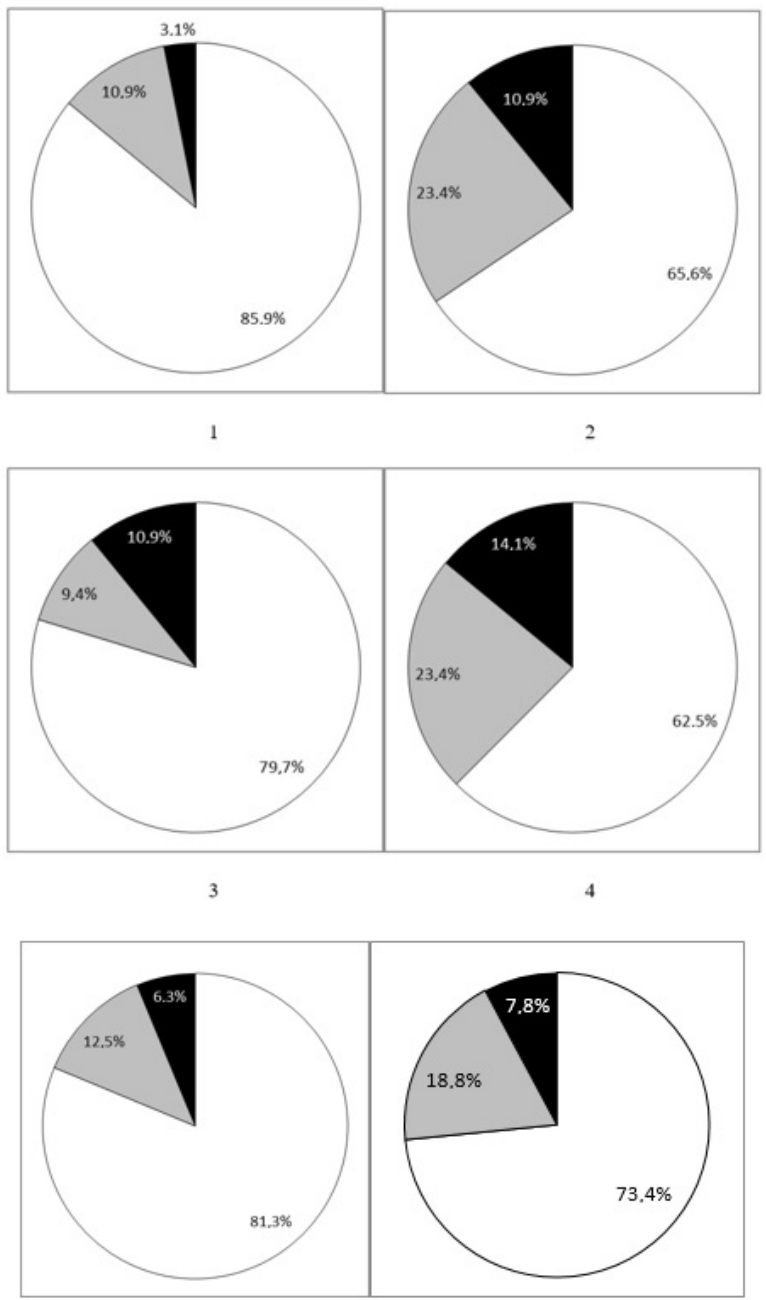

6

Fig. 1. Survey results

The obtained empirical data were applied to analyze the truth of the developed hypotheses. From $80 \%$ to $94.7 \%$ of students were convinced that mobile blogging could develop journalism skills. The average number of such students in four universities was $85.9 \%$. Only two people $(3.1 \%)$ of all the sample disagreed with this statement, while $10.9 \%$ of respondents found it difficult to answer. Consequently, hypothesis H1 was affirmed with a high degree of certainty.

From $55.6 \%$ to $75 \%$ of participants shared an opinion that mobile blogging motivates students to acquire new knowledge (the average value corresponds to $65.6 \%$ ). The number of respondents with an opposite viewpoint varied from 1 to 3 people 
$(10.9 \%)$. Only $23.4 \%$ of all the surveyed were difficult to answer. Considering this, the hypothesis $\mathrm{H} 2$ was confirmed.

From $66.7 \%$ to $84.2 \%$ of students were satisfied with how blogging mobile training was organized. The average number of such students for considered universities equaled $79.7 \%$. The number of respondents who were dissatisfied with the training process ranged from 1 to 2 people, which, on average, amounted to $10.9 \%$. Only $9.4 \%$ of participants were not sure about their answer. From $55.6 \%$ to $73.7 \%$ (on average, $62.5 \%$ ) of students stated the there is a need to increase the study time devoted to journalistic blogs. From 2 to 3 people (14.1\%) in each university disagreed with this statement, while $23.4 \%$ of respondents experienced difficulties in answering. These data enabled the confirmation of hypothesis $\mathrm{H} 3$.

From $73.3 \%$ to $88.9 \%$ of respondents admitted that blogging is crucial for the successful journalist career ( $81.3 \%$ on average). Only 4 students (6.3\%) had an opposite opinion, while $12.5 \%$ of respondents neither agreed nor disagreed. From $72.2 \%$ to $75 \%$ of the students (on average, $73.4 \%$ ) wanted to develop personal blogs in the future, $7.8 \%$ do not intend to continue posting materials, and $18.8 \%$ were not sure on this point. Therefore, hypothesis $\mathrm{H} 4$ was also accepted.

\section{Discussion}

Within the results' analysis, a slight discrepancy should be noted in the number of journalism students who admitted the importance of blogging for a successful career (52 people) with those who intend to continue posting materials (47 people). There were several students who realized the significance of developing a journalistic blog, although, did not want to take advantage of it. This fact could be explained by students' passivity concerning the future. Nevertheless, during the survey, all $100 \%$ of the participants had active blogs that were as close as possible to the professional journalistic environment. Besides, a sharp increase in the number of blog authors among journalism students should be pointed out. It raised from 20 people (30.2\%) to 47 people $(73.4 \%)$, which corresponds to an increase of 2.35 times. It is especially significant for Kazakhstan universities, where fewer students than in Russia had blogs before the experiment. In KSU, the number of blogging students increased from 4 to 13 people (by 325\%) and in IITU from 2 to 9 people (by $450 \%$ ).

A similar study was conducted in the UK in 2014 among six interviewees selected from a population of 100 journalism undergraduates who had been actively writing a blog for more than 12 months [4]. At the same time, blogging was not required by the curriculum; however, it was considered as one of the factors which should enhance students' employment prospects. Therefore, Stoker's research was aimed at analyzing the development of universal competencies that are in demand in the labor market. The results of his paper revealed that students improved such skills as networking, communication in a team and with readers, IT knowledge, problem-solving, creative thinking, time management, customer awareness, adaptability to changing situations, and self-confidence. As a consequence, it was concluded that blogging should be 
included in the university curriculum. Though, only six students were selected for the interview, which does not allow recognizing this sample as sufficiently reliable.

Related conclusions were obtained in a project carried out jointly by the University of the Basque Country in Spain, and the Mato Grosso do Sul Federal University in Brazil [16]. As part of the project, a training course on Online Journalism and Reporting, which met the requirements of the European Higher Education Area (EHEA), was developed and introduced for students from both universities. The course had 60 teaching hours, of which 32 were lectures and 28 practical classroom sessions. Practical classes were devoted to the online development of a blog in the news format, the dissemination of information on blogs on social networks, communication with readers, students' mutual assessment of each other according to the questionnaire template. In contrast to the experiment described in the present article, Spanish and Brazilian journalism students worked in groups of 4-5 people. A significant part of the blog service was carried out through the use of mobile devices and applications, but the study did not focus on this. Researchers noted the development of competencies necessary for the generation of multimedia content and cooperation when working in reporter teams, as well as basic skills for writing news of a given volume in a limited time. Unfortunately, the mentioned article does not contain relevant empirical data confirming the analyzed results.

It also seems beneficial to consider the paradigm shift in the use of blogs in education that has occurred during the past 10-15 years. The use of mobile technologies was developed a little later and his research is actively developing now [29]. For example, the US study, conducted in 2007 among 189 randomly selected journalists and 239 journalism educators (428 in total), showed that only $21 \%$ of all participants maintained a blog [21]. Chung et al. evaluated various aspects of blogs' usefulness, which was rated no higher than 2.5 on a five-point scale. Professional journalists appeared to use blogs less often than teachers and use them primarily with access via mobile devices [20]. At the same time, it was stated that blogs are essential for students (rated as 3.75 on a five-point scale).

The study among 105 journalism students at Auckland University of Technology (New Zealand) revealed that only $12 \%$ of students were active bloggers, while less than $50 \%$ visited various news blogs on a regular basis [22]. Nevertheless, blogging is now positioned as a mandatory skill of a modern journalist. For this reason, mobile blogging entered the educational process only in the last decade.

\section{Conclusion}

The present research analyzed the effectiveness of the organization of mobile training journalism students through the use of mobile blogs. The study was conducted among 71 undergraduate journalism students of two Russian (ASU, PNU) and two Kazakhstan universities (KSU, IITU). In the educational process of these institutions, innovative techniques for mobile teaching journalism students were introduced, and the appropriate methods for conducting practical classes in specialized disciplines were applied. During the practical training, each surveyed person prepared texts on 
topics related to the subject of academic disciplines. Students worked in groups of 2-3, completing assignments for mutual assessment and commenting on partners' materials. This allowed journalism students to enhance not only professional but also universal and general competencies.

At the end of the semester, in which mobile blogging methods were introduced, the survey among the involved students was carried out. The examination revealed participants' positive impressions from mobile educational blogging, which is confirmed by respectively high estimations of various blogging aspects (from $55.6 \%$ to $94.7 \%$, depending on the questionnaire section). During one training semester, the number of students mobile blogging on an ongoing basis has grown by 2.35 times (from 20 to 47 people). The obtained experimental data confirmed all four tested hypotheses. As a consequence, it can be stated that blogging develops journalistic skills, stimulates journalism students to acquire new knowledge, ensures the satisfaction of students with the educational process, and increases the motivation to engage in professional activities.

The practical significance of the results obtained lies in the fact that the proposed approach allows the effective use of blogs in the organization of journalism students' training. The scientific novelty of the article is due to the fact that it analyzes the effectiveness of blog development in organizing journalism education. Experimental data, presented in the present paper, confirm the usefulness of student blogs. The research findings can contribute to the organization of teaching journalistic disciplines in higher educational institutions.

\section{References}

[1] Gladilina, I., Yumashev, A.V., Avdeeva, T.I., Fatkullina, A.A., Gafiyatullina, E.A. (2018). Psychological and pedagogical aspects of increasing the educational process efficiency in a university for specialists in the field of physical education and sport. Espacios, 39(21): 11.

[2] Pereira, F.H. (2020). The Effects of Innovation on the Careers of Journalists. In Digitalization of Society and Socio-political Issues 2: Digital, Information and Research. John Wiley \& Sons, pp. 27-39. https://doi.org/10.1002/9781119694885.ch3

[3] Vartan ova, E.L. (2018). On the basic concepts of the "digital media field" in Russian media research. Medialmanach, 2: 8-16.

[4] Stoker, R. (2015). An investigation into blogging as an opportunity for work-integrated learning for journalism students. Higher Education, Skills and Work-based Learning, 5(2): 168-180. https://doi.org/10.1108/heswbl-01-2014-0002

[5] Dugin, E.Ya. (2017). Traditions and innovations in understanding the media and journalism. Bulletin of Moscow University, Series 10: Journalism, 3: 3-17.

[6] Dernbach, B., Illg, B. (2020). Journalism and Journalism Education in Developing Countries. Manipal Universal Press.

[7] Abu-Shanab, E., Alsmadi, N. (2019). Blogs as an Effective Social Media Tool in Education. In Society for Information Technology \& Teacher Education International Conference. Association for the Advancement of Computing in Education (AACE), pp. 367-373.

[8] Drigas, A., Angelidakis, P. (2017). Mobile applications within education: An overview of application paradigms in specific categories. International Journal of Interactive Mobile Technologies, 11(4): 17-29. https://doi.org/10.3991/ijim.v11i4.6589 
[9] Garifullin, V.Z., Zakirov, L.R. (2018). The Role of Blogosphere in National Internet Space Development. Proceedings of Kazan University. Humanities Series, 160(4): 872-883.

[10] Cherkasov, A.A., Bratanovskii, S.N., Koroleva, L.A., Zimovets, L.G. (2019). Development of the School Education System in the Province of Vologda (1725-1917). Part 2. European Journal of Contemporary Education, 8(2): 418-424. https://doi.org/10.13187/ejced. $\underline{2019.2 .418}$

[11] Thorsen, E., Jackson, D. (2018). Seven characteristics defining online news formats: Towards a typology of online news and live blogs. Digital Journalism, 6(7): 847-868. https://doi.org/10.1080/21670811.2018.1468722

[12] Cherkasov, A.A., Bratanovskii, S.N., Koroleva, L.A., Zimovets, L.G. (2019). Development of School Education in the Vologda Governorate (1725-1917). Part 1. European Journal of Contemporary Education, 8(1): 208-214. https://doi.org/10.13187/ejced.2019.1 .208

[13] Gatov, V. (2015). Post Journalist: Journalism after the digital transition. Publishing Solutions Agency, Moscow.

[14] Newman, N. (2018). Journalism, media, and technology trends and predictions. Reuters Institute for the Study of Journalism.

[15] Kurambayev, B., Freedman, E. (2020). Ethics and Journalism in Central Asia: A Comparative Study of Kazakhstan, Kyrgyzstan, Tajikistan and Uzbekistan. Journal of Media Ethics, 35(1): 31-44. https://doi.org/10.1080/23736992.2019.1700119

[16] Larrondo, A., Agirreazkuenaga, I., Peña, S. (2017). The Use of Digital Means in the Teaching and Learning of Multiplatform and Social Media News Reporting. In Proceedings of European Conference on Education (ECE’2017). Brighton, UK, pp. 283-294.

[17] Picard, R.G. (2020). Deficient tutelage: Challenges of contemporary journalism education. In Toward. Ryerson Journalism Research Centre, Toronto, pp. 4-10.

[18] Starov, O., Sklyar, V., Kharchenko, V., Boyarchuk, A., Phillips, C. (2014). A student-inthe-middle approach for successful university and business cooperation in IT. In Proceedings of the University-Industry Interaction Conference (UIIN'2014). Barcelona, Spain, pp. 193-207.

[19] Beier, M.E., Kim, M.H., Saterbak, A., Leautaud, V., Bishnoi, S., Gilberto, J.M. (2019). The effect of authentic project-based learning on attitudes and career aspirations in STEM. Journal of Research in Science Teaching, 56(1): 3-23. https://doi.org/10.1002/tea.21465

[20] Al-Kinani, M.N.H., Adetunmbi, S.B., Hussain, A. (2020). Usability Testing of Mobile Flipboard Application on both Non-Users and Novice Users. International Journal of Interactive Mobile Technologies, 14(5): 47-56. https://doi.org/10.3991/ijim.v14i05.13341

[21] Chung, D.S., Kim, E., Trammell, K.D., Porter, L.V. (2007). Uses and perceptions of blogs: A report on professional journalists and journalism educators. Journalism \& Mass Communication Educator, 62(3): 305-322. https://doi.org/10.1177/107769580706200306

[22] Hirst, M., Treadwell, G. (2011). Blogs bother me: Social media, journalism students and the curriculum. Journalism Practice, 5(4): 446-461. https://doi.org/10.1080/17512786.201 1.555367

[23] Hodgson, P., Wong, D. (2011). Developing professional skills in journalism through blogs. Assessment \& Evaluation in Higher Education, 36(2): 197-211. https://doi.org/10.1080/0 2602930903229868

[24] McEnnis, S. (2019). A whole new ball game: How Sky Sports News journalists are learning from the academy. Australian Journalism Review, 41(2): 169-181. https://doi.org/10 $.1386 /$ ajr 000041

[25] Grigoryan, S.V. (2012). The Blogosphere as a platform for training Internet-journalist. Peoples' Friendship University of Russia: Literary Studies, Journalism, 4: 140-145. 
[26] Myasnikov, I. (2017). "Faculty of Journalism 2030": Is the Impossible Possible? Strategic sessions on professional education at the Faculty of Journalism of Tomsk State University. Journalism Issues, 2: 124-129.

[27] Ershov, Yu.M. (2018). What the Future Journalist Will Be Like (Some Speculations about the Modernization of Educational Programs). Bulletin of Moscow University: Journalism, 5: 119-136.

[28] Kokhanova, L.A., Chereshneva, Yu.E. (2018). Digital culture as a philological journalist training component (some results of the pilot study). Bulletin of the Volga University V. N. Tatishcheva, 1(4): 193-198.

[29] El-Sofany, H., El-Haggar, N. (2020). The Effectiveness of Using Mobile Learning Techniques to Improve Learning Outcomes in Higher Education. International Journal of Interactive Mobile Technologies, 14(8): 4-18. https://doi.org/10.3991/ijim.v14i08.13125

[30] Kim, M.N., Pak, E.M. (2020). Genres of print and electronic media. Piter Publishing House, St. Petersburg.

\section{Authors}

Rozhkov Alexandr Viktorovich is a Candidate of Philological Sciences, Associate Professor of the Department of UNESCO, International Journalism and Media in Society, Al-Farabi Kazakh National University, Almaty, Kazakhstan. Email: alex.roz hkov11@rambler.ru, Alexander.Rozhkov@kaznu.kz

Bulatova Madina Bulatovna is a Master of Social Sciences, Doctoral Candidate of the Department of Journalism and Political Science, L.N. Gumilyov Eurasian National University, Nur-Sultan, Kazakhstan.

Noda Larissa Pavlovna is a Senior Lecturer of the Department of Print and Electronic Media, Al-Farabi Kazakh National University, Almaty, Kazakhstan.

Article submitted 2020-09-12. Resubmitted 2020-10-26. Final acceptance 2020-10-27. Final version published as submitted by the authors. 